\title{
COVID-19: lessons in risk communication and public trust
}

\section{Don Nutbeam ${ }^{a, b, c, d}$}

a Editor-in-Chief, Public Health Research \& Practice

b School of Public Health, University of Sydney, NSW, Australia

c Sax Institute, Sydney, NSW, Australia

d Corresponding author: don.nutbeam@sydney.edu.au

\section{Article history}

Publication date: June 2020

Citation: Nutbeam D. COVID-19: lessons in risk communication and public trust. Public Health Res Pract. 2020;30(2):e3022006. https://doi.org/10.17061/phrp3022006
These are challenging times to be in government. Grappling with an unprecedented global pandemic with unknowable economic and social consequences, politicians and policy makers have had to plot a course to manage the epidemic while preserving the social and economic fabric of the country. In most countries, the response to the epidemic has also been characterised by an unusually high level of dependence by those in government on the best available scientific advice. The countries where the epidemic has been best controlled are those that responded quickly and decisively to the public health advice. ${ }^{1}$ The response to the epidemic has depended on a high level of public trust in government information and unprecedented compliance with advice on personal distancing and hand hygiene.

Throughout the epidemic, the public have sought clear and consistent advice from their governments. For governments, providing such guidance has not been easy when there are many unknowns and uncertainties. Many governments stuttered at the start of the pandemic, and were slow to provide clarity and certainty. When clarity and consistency of message was missing, people turned to alternative sources of information in the mainstream and digital media. This resulted in confusion as unreliable and misleading information circulated, especially through social media. ${ }^{2-4}$

Slowly the fog is lifting. Our understanding of coronavirus disease 2019 (COVID-19) continues to improve. Although there are still few reliable options for treatment and no vaccine, in many countries, the public have demonstrated great social discipline and continued to trust governments and the scientific advice they receive. ${ }^{1,5}$ There is a long way to go and there are many threats to the fragile consensus between governments and their citizens that has been achieved so far. In many countries, the public have received support to weather the immediate economic shock of population 'lockdown'. As governments attempt to restart the economy these protections will decline and the economic impact will be patchy. The longer-term social and mental health consequences of the economic shock, enforced isolation and continuing physical distancing are not yet clear and may yet be as profound as the impact on physical health especially in those countries with lower rates of infection.

Effective public communication remains vital for maintaining physical distancing rules, and managing the risk of second and third waves of the epidemic. The generic social marketing campaigns that served well in the first phase of the epidemic will need to evolve to ensure they maintain impact and reach - especially in countries with highly diverse populations. This will 
inevitably involve more nuanced and targeted messaging that uses a wider range of messages and media channels than has characterised the first phase of the pandemic. ${ }^{6}$

In this edition of the Journal, we have four papers reflecting important perspectives to the response to COVID-19 in Australia and elsewhere. The paper by Leask and Hooker illustrates perfectly the challenge of communicating to the public clearly and decisively during a period of uncertainty, and highlights the consequences of small delays and inferred contradictions in communication about risk to children related to school attendance. ${ }^{7}$ The paper offers practical guidance on how this might be done better in the future. The paper by Currie and colleagues provides an excellent example of how complex modelling techniques can be applied to improve understanding of the potential contribution of the Australian smartphone app to COVID-19 surveillance and contact tracing. ${ }^{8}$ The findings indicate that the app can play a significant role in mitigating the risk of a second wave of the epidemic, but this is dependent on achieving a high level of public uptake and use of the app. The third COVID-19 themed paper, by Smith and Lim, focuses our attention on the immediate and longer-term impact of social distancing and isolation on mental health. ${ }^{9}$ They emphasise that the current COVID-19 control measures may exacerbate and/or accelerate poor mental health outcomes among individuals who were already experiencing loneliness and social isolation, arguing that the pandemic has highlighted the need for collaborative, evidence-based action to address the under-recognised public health issue of social isolation and loneliness. In the final themed paper, Ratzan and colleagues highlight the critical need to improve global health communication, where health communicators are more proactive in tackling risk communication challenges. ${ }^{10}$ The authors describe how to build preparedness capacity as we move from the acute phase of the pandemic to the 'next normal', with likely prevention achieved through vaccination and societal COVID-19 resilience.

These papers provide examples of the profound and continuing impact of the global COVID-19 pandemic on the physical, social and mental health of our communities. Maintaining the fragile consensus between governments, their scientific advisers, and their citizens is critical to the successful control of the epidemic. This consensus will be sustained by mutual trust built on effective communication - between scientists and policy makers, and between governments and their populations.

\section{Peer review and provenance}

Internally reviewed, invited.

\section{Competing interests}

None declared.

\section{Author contributions}

DN is the sole author.

\section{References}

1. Oksanen A, Kaakinen M, Latikka R, Savolainen I, Savela N, Koivula A. Regulation and trust: 3-month follow-up study on COVID-19 mortality in 25 European countries. JMIR Public Health Surveill. 2020;6(2):e19218.

2. Depoux A, Martin S, Karafillakis E, Preet R, WilderSmith $\mathrm{A}$, Larson $\mathrm{H}$. The pandemic of social media panic travels faster than the COVID-19 outbreak. J Travel Med. 2020;27(3):taaa031.

3. Limaye RJ, Sauer M, Ali J, Bernstein J, Wahl B, Barnhill A, Labrique A. Building trust while influencing online COVID-19 content in the social media world. Lancet Digit Health. 2020;2(6):e277-8.

4. World Health Organization. Geneva: WHO; 2020. Coronavirus disease (COVID-19) advice for the public: myth busters [cited 2020 Jun 10]. Available from: www. who.int/emergencies/diseases/novel-coronavirus-2019/ advice-for-public/myth-busters

5. Newgate Australia. Sydney: Newgate Communications; 2020. Australia's response to COVID-19 has reached a rare consensus, as community wants to stay the course on virus fight; 2020 Apr 16 [cited 2020 Jun 10]. Available from: www.newgatecomms.com.au/australiasresponse-to-covid-19-has-reached-a-rare-consensus-ascommunity-wants-to-stay-the-course-on-virus-fight/

6. Betsch C, Wieler LH, Habersaat K; COSMO group. Monitoring behavioural insights related to COVID-19. Lancet. 2020;395(10232):1255-6.

7. Leask J, Hooker C. How risk communication could have avoided controversy about school closures in Australia during the COVID-19 pandemic. Public Health Res Pract. 2020;30(2):e3022007.

8. Currie DJ, Peng CQ, Lyle DM, Jameson BA, Frommer MS. How much can the Australian smartphone app help to control COVID-19? Public Health Res Pract. 2020;30(2):e3022009.

9. Smith B, Lim MH. How the COVID-19 pandemic is focusing attention on loneliness and social isolation. Public Health Res Pract. 2020;30(2):e3022008.

10. Ratzan SC, Sommariva S, Rauh L. Enhancing global health communication during a crisis: lessons from the COVID-19 pandemic. Public Health Res Pract. 2020(2):e3022010.

\section{Copyright: (ㄷ) (i) (2) (2)}

(C) 2020 Nutbeam. This article is licensed under the Creative Commons Attribution-NonCommercial-ShareAlike 4.0 International Licence, which allows others to redistribute, adapt and share this work non-commercially provided they attribute the work and any adapted version of it is distributed under the same Creative Commons licence terms. See: www.creativecommons.org/licenses/by-nc-sa/4.0/ 